\title{
FAKTOR YANG BERHUBUNGAN DENGAN KUNJUNGAN K4 PADA IBU HAMIL DI WILAYAH KERJA PUSKESMAS KOTA KUALA SIMPANG KABUPATEN ACEH TAMIANG TAHUN 2019
}

\author{
Nurbaiti $^{1}$, Donal Nababan², Asima Sirait ${ }^{3}$ \\ ${ }^{1}$ Program Studi Magister Ilmu Kesehatan Masyarakat, Universitas Sari Mutiara Indonesia Medan \\ Email:nur.baiti45@yahoo.com \\ ${ }^{2}$ Direktorat Pasca Sarjana Ilmu Kesehatan Masyarakat, Universitas Sari Mutiara Indonesia Medan \\ Email: nababan_donal@yahoo.com \\ ${ }^{3}$ Universitas Sari Mutiara Indonesia Medan \\ Email: asimasirait@yahoo.co.id
}

\begin{abstract}
ABSTRAK
Selama kehamilan dapat dilakukan pemantauan rutin dengan menggunakan cakupan K1 dan K4. Tahun 2017 cakupan K4 berjumlah 96,7\%. Sedangkan pada tahun 2018, cakupan K4 pada ibu hamil berjumlah $356(68,5 \%)$ dari sasaran ibu hamil berjumlah 519 (100\%). Dari data tersebut dapat diketahui bahwa pada Tahun 2018 cakupan K4 pada ibu hamil menurun dibandingkan dengan cakupan K4 di Tahun 2017.Tujuan penelitian untuk mengetahui hubungan pengetahuan, paritas, dukungan keluarga, ketersediaan alatpemeriksaan kehamilan, jangkauan ketempat pelayanan kesehatan, dukungan petugas kesehatan serta faktor yang paling dominan terhadap kunjungan K4 pada ibu hamil di Wilayah Kerja Puskesmas Kota Kualasimpang Kabupaten Aceh Tamiang. Jenis penelitian adalah analitik dengan metode rancangan crossectional. Populasi penelitian ini adalah ibu hamil trimester III yang memeriksakan kehamilannya di Wilayah Kerja Puskesmas Kota Kualasimpang Kabupaten Aceh Tamiang berjumlah 356 dengan sampel menggunakan rumus Slovin sebanyak 78 orang. Teknik pengambilan sampel menggunakan teknik accidental sampling. Dari hasil uj iregresi logistic berganda dengan nilaip value $=0.25$, diperoleh bahwa ada hubungan yang signifikan pengetahuan $(\mathrm{p}=0.000, \mathrm{PR}=0.075)$, paritas $(\mathrm{p}=0.001, \mathrm{PR}=15.863)$, ketersediaan alat pemeriksaan kehamilan $(\mathrm{p}=0.011, \mathrm{PR}=0.132)$, jangkauan ketempat pelayanan kesehatan $(\mathrm{p}=0.006, \mathrm{PR}=0.112)$, dukungan $(\mathrm{p}=0.007, \mathrm{PR}=0.084)$, variabel yang paling dominan adalah paritas $(\mathrm{p}=0.001 ; \mathrm{PR}=15.863 ; 95 \% \mathrm{CI}: 3.221$ 78.114)yang berarti bahwa responden dengan Paritas multigravida mempunyai risiko tidak melakukan kunjungan K4 15.863 kali lebih besar dibandingkan paritas primigravida. Diharapkan kepada ibu hamil agar lebih aktif dan giat dalam melakukan kunjungan K4 agar terdeksi segala kemungkinan yang dapat terjadi sehingga terhindar dari bahaya selama kehamilan maupun menjelang persalinan.
\end{abstract}

Kata Kunci: Analisis Multivariat; Ibu Hamil; Kunjungan K4

\begin{abstract}
During pregnancy routine monitoring can be done using K1 and K4 coverage. In 2017 K4 coverage was $96.7 \%$. Whereas in 2018, K4 coverage for pregnant women amounted to 356 (68.5\%) of the target pregnant women amounted to 519 (100\%). From these data it can be seen that in 2018 the coverage of K4 in pregnant women decreased compared to the K4 coverage in 2017. The aim of the study was to determine the relationship of knowledge, parity, family support, availability of pregnancy check-ups, coverage of health services, support of health workers and other factors. most dominant on $K 4$ visits for pregnant women in the Work Area of Kualasimpang City Health Center, Aceh Tamiang Regency. This type of research is analytic with cross-sectional design methods. The population of this study was the third trimester pregnant women who examined their pregnancies in the Work Area of Kualasimpang City Health Center in Aceh Tamiang Regency with a total of 356 samples using a Slovin formula of 78 people. The sampling technique uses accidental sampling technique. From the results of multiple logistic regression tests with a value of value $=0.25$, it was found that there was a significant relationship of knowledge $(p=0.000, P R=0.075)$, parity $(p=0.001, P R=15,863)$, the availability of a pregnancy checkup $(p=0.011, P R=0.132)$, range of health services $(p=0.006, P R=0.112)$, support $(p=0.007, P R=$ $0.084)$, the most dominant variable is parity ( $p=0.001 ; P R=15,863 ; 95 \%$ CI: 3,221- 78,114) which means that respondents with multigravida parity have a risk of not doing $K 4$ visits 15,863 times greater than primigravida parity. It is expected that pregnant women will be more active and active in conducting K4 visits in order to detect all possibilities that can occur so as to avoid danger during pregnancy or before delivery.
\end{abstract}

Keywords: Multivariate Analysis; Pregnant mother; K4 visit 


\section{PENDAHULUAN}

\section{Latar Belakang}

Kehamilan adalah pemeliharaan janin dalam kandungan yang disebabkan pembuahan sel telur oleh sperma (Irianto, 2014). Selama kehamilan dapat dilakukan pemantauan rutindengan menggunakan cakupan K1 dan K4. Cakupan K4 adalah jumlah ibu hamil yang telah memperoleh pelayanan pemeriksaan kehamilan sesuai dengan standar paling sedikit empat kali sesuai jadwal yang dianjurkan.Kunjungan K4 digunakan untuk menilai kualitas pelayanan kesehatan ibu hamil serta frekuensi pada setiap periode trimester saat melakukan pemeriksaan kehamilan. (Kemenkes RI, 2015).

Menurut Global Health Observatory (GHO), jumlah kematian ibu menurun 43\% di tahun 1990 dan 2015. Secara global, angka kematian ibu turun hampir 44\% selama 25 tahun terakhir. Diperkirakan kematian ibu sebesar 303.000 jiwa atau sekitar 216/100.000 kelahiran hidup, 830 perempuan meninggal setiap harinya akibat komplikasi kehamilan dan proses kelahiran. Kematian ibu adalah kematian selama kehamilan atau dalam periode 42 hari setelah berakhirnya kehamilan, yang diakibatkan oleh kehamilan (WHO, 2016).

Berdasarkan data Riskesdas Tahun 2018, proporsi pemeriksaan kehamilan K4 pada perempuan umur 10-54 tahun di Indonesia pada tahun 2013 adalah sebanyak 70.0\% dan meningkat menjadi 74.1\% di tahun 2018, sedangkan menurut hasil SDKI tahun 2017 mencapai 77\%. Demikian hal ini menjadi suatu masalah dalam menurunkan angka kematian ibu. Tingginya AKI di Indonesia disebabkan oleh beberapa penyebab yaitu pendarahan (26,99\%), eklampsia (23\%), infeksi $(10,99 \%)$, komplikasi puerpurium (8\%), trauma obstetrik (5\%), emboli obstetrik (5\%), partus lama (5\%), abortus (5\%) dan lain-lain (10,99\%). Penyebab AKI bisa dideteksi dengan melakukan kunjungan K4 dalam pemeriksaan kehamilan.

Pada tahun 2014 tercatat cakupan K4 adalah 86,70\%. Untuk cakupan K4, terlihat masih belum mencapai target Rencana Strategis (Renstra) yaitu 95\% untuk cakupan pelayanan kesehatan ibu hamil K4 (Kemenkes RI, 2015).Pada tahun 2015, cakupan K4 yaitu 87,48\%. Angka tersebut telah memenuhi target Rencana Strategis (Renstra) Kementrian Kesehatan tahun 2015 untuk cakupan K4 sebesar 72\%. Namun, target ini lebih rendah dari target Renstra di tahun 2014 yakni 95\%. Akan tetapi, meskipun target Renstra diturunkan masih terdapat lima provinsi yang belum mencapai target tersebut yaitu Papua, Papua Barat, Maluku, Nusa Tenggara Timur, dan Sulawesi Tengah (Kemenkes RI, 2016).

Profil Kesehatan Kabupaten Aceh Tamiang Tahun 2017, target cakupan pelayanan kesehatan ibu hamil (K4)berjumlah 95\%, kemudian pada tahun 2018-2019 Dinas Kesehatan Kabupaten Aceh Tamiang menetapkan target kunjungan K4 sebesar $100 \%$.

Salah satu faktor yang menyebabkan tidak tercapainya kunjungan K4 adalah munculnya fenomena dimana pemeriksaan kehamilan pada ibu hamil akan membuat ibu lebih siap dengan kehamilannya yaitu diikuti dengan semakin dewasanya usia ibu atau berdasarkan pengalaman pribadi maupun pengetahuan berdasarkan pengalaman orang lain. Oleh karena itu, kebanyakan ibu merasa tidak perlu melakukan pemeriksaan kehamilan sehingga menyebabkan tidak tercapainya kunjungan minimal 4 kali (K4).

Menurut Rohan, H, \& Siyoto,S, 2013 dalam Cholifah (2015), ibu hamil yang melakukan K4 dipengaruhi oleh beberapa faktor. Faktor-faktor yang mempengaruhi ibu hamil dalam melakukan pemeriksaankehamilan adalah usia, pendidikan, pekerjaan, paritas, pengetahuan, 
fasilitas pelayanan pemeriksaan kehamilan, dukungan keluarga dan jangkauan ke tempat pelayanan kesehatan.

Berdasarkan survei awalyang dilakukan diWilayah Kerja Puskesmas Kota Kualasimpang Aceh Tamiang, pada Tahun 2017 cakupan K4 berjumlah 506 (96,7\%) dari sasaran ibu hamil berjumlah $523(100 \%)$. Sedangkan pada tahun 2018, cakupan K4 pada ibu hamil berjumlah $356(68,5 \%)$ dari sasaran ibu hamil berjumlah 519 (100\%). Dari data tersebut dapat diketahui bahwa pada Tahun 2018 cakupan K4 pada ibu hamil menurun dibandingkan dengan cakupan K4 di Tahun 2017.

Dari hasil wawancara 12 orang ibu hamil diwilayah kerja Puskesmas Kota Kualasimpang Aceh Tamiang, terdapat 3 orang ibu hamil memilih tidak melakukanpemeriksaan kehamilan dengan alasan jangkauan ketempat pelayanan kesehatan yangjauh, 2 orang tidak mau melakukan pemeriksaan kehamilan karena kurangnya pengetahuan tentang pentingnya kunjungan K4 selama kehamilan, 1 orang tidak melakukan pemeriksaan kehamilan ke puskesmas karena ketersediaan alat pemeriksaan kehamilan yang kurang lengkap, 2 orang jarang melakukan pemeriksaan kehamilan karena tidak adanya faktor dukungan dari keluarga, 2 orang lainnya rutin melakukan pemeriksaan kehamilan karena terdapat riwayat paritas, dan 2 orang karena kurangnya informasi dari petugas kesehatan tentang pentingnya pemeriksaan kehamilan.

Dari latar belakang diatas, maka peneliti tertarik melakukan penelitian tentang "Faktor Yang Berhubungan Dengan Kunjungan K4 Pada Ibu Hamil Di Wilayah Kerja Puskesmas Kota Kualasimpang Kabupaten Aceh Tamiang Tahun 2019”.

\section{METODE PENELITIAN}

Penelitian ini menggunakan pendekatan analitik dengan menggunakan metode rancangan crossectional di lakukan Di Wilayah Kerja Puskesmas Kota Kuala Simpang dengan menggunakan data primer dan data skunder. Populasi dalam penelitian ini adalah ibu hamil trimester III yang memeriksakan kehamilannya di Wilayah Kerja Puskesmas Kota Kualasimpang Aceh Tamiang.Jumlah ibu hamil trimester III yang melakukan pemeriksaan kehamilan di tahun 2018 sebanyak 356 orang. Sampel Dalam penelitian ini sampel berjumlah 78 Orang. Pengambilan sampel dilakukan dengan menggunakan teknik accidental sampling.

Metode yang digunakan dalam penelitian ini menggunakan Data primer diperoleh dengan menggunakan kuesioner yang telah dipersiapkan untuk mengetahui pengetahuan ibu hamil tentang kunjungan $\mathrm{K} 4$, paritas, ketersediaan alat pemeriksaan kehamilan, jangkauan ketempat pelayanan kesehatandukungan keluarga, dan dukungan petugas kesehatan, dan menggunakan Data sekunder diperoleh dari Puskesmas Kota Kualasimpang Kabupaten Aceh Tamiang berupa data jumlahkeseluruhan ibu hamil yang datang melakukan kunjungan pemeriksaan kehamilan di tahun 2018.

\section{HASIL DAN PEMBAHASAN}

Hasil dalam penelitian ini disajikan dalam analisi univariat, analisis bivariat dan analisis multivariat. 


\section{Analisis Univariat}

Tabel 1. Distribusi Frekuensi Karakteristik Respoden Ibu Hamil Trimester III Dalam Melakukan Kunjungan K4 di Wilayah KerjaPuskesmas Kota Kualasimpang Aceh Tamiang Tahun 2019

\begin{tabular}{llcc}
\hline No. & Karakteristik & Frekuensi(n) & Persentase(\%) \\
\hline & Umur & & \\
\hline 1 & $<20$ Tahun & 7 & 9.0 \\
2 & 20-35 Tahun & 63 & 80.0 \\
3 & $>35$ Tahun & 8 & 10.3 \\
\hline & Total & 78 & 100.0 \\
\hline & Pekerjaan & & 39.7 \\
\hline 1 & Tidak Bekerja & 31 & 60.3 \\
2 & Bekerja & 47 & 100.0 \\
\hline & Total & 78 & 69.3 \\
\hline & Pendidikan & & 30.7 \\
\hline 1 & Rendah & 54 & 100.0 \\
\hline & Tinggi & 24 & \\
\hline
\end{tabular}

Berdasarkan Tabel 1, diketahui umur responden yang melalukan kunjungan $\mathrm{K} 4$ dalam dalam kehamilan mayoritas 20-35 Tahun sebanyak 63 orang (80.0\%). Pekerjaan mayoritasbekerjasebanyak 47 orang $(60,3 \%)$. Pendidikan mayoritas rendah sebanyak 54 orang $(69.3 \%)$

Tabel 2. Distribusi Frekuensi Pengetahuan Ibu Hamildi Wilayah Kerja Puskesmas KotaKualasimpang Kabupaten Aceh Tamiang Tahun 2019

\begin{tabular}{|c|c|c|c|}
\hline No & Pengetahuan Ibu Hamil & $\mathbf{n}$ & $\%$ \\
\hline 1 & Kurang & 43 & 55.1 \\
\hline 2 & Cukup & 21 & 26.9 \\
\hline 3 & Baik & 14 & 17.9 \\
\hline & Jumlah & 78 & 100.0 \\
\hline
\end{tabular}

Berdasarkan tabel 4.2 di atas dapat dilihat bahwa pengetahuan ibu hamil mayoritas kurang sebanyak 43 orang $(55.1 \%)$.

Tabel 3. Distribusi Frekuensi Paritas di Wilayah Kerja Puskesmas Kota Kualasimpang Kabupaten Aceh Tamiang Tahun 2019

\begin{tabular}{clcc}
\hline No & \multicolumn{1}{c}{ Paritas } & n & \% \\
\hline 1 & Primigravida & 19 & 24.4 \\
2 & Multigravida & 31 & 39.7 \\
3 & Grandemultigravida & 28 & 35.9 \\
\hline & Jumlah & $\mathbf{7 8}$ & $\mathbf{1 0 0 . 0}$
\end{tabular}

Berdasarkan tabel 3. di atas dapat dilihat bahwa paritas mayoritas Multigravida sebanyak 31 orang $(39.7 \%)$. 
Tabel 4. Distribusi Frekuensi Ketersediaan Alat Pemeriksaan Kehamilan di Wilayah Kerja Puskesmas Kota Kualasimpang Kabupaten Aceh Tamiang Tahun 2019

\begin{tabular}{|c|c|c|c|c|}
\hline No & $\begin{array}{l}\text { Ketersediaan } \\
\text { Pemeriksaan Kehamilan }\end{array}$ & Alat & $\mathbf{n}$ & $\%$ \\
\hline 1 & Tidak Lengkap & & 43 & 55.1 \\
\hline 2 & Lengkap & & 35 & 44.9 \\
\hline & Jumlah & & 78 & 100.0 \\
\hline
\end{tabular}

Berdasarkan tabel 4. di atas dapat dilihat bahwa ketersediaan alat pemeriksaan kehamilan mayoritas tidak lengkap sebanyak 43 orang (55.1\%).

Tabel 5.Distribusi Frekuensi Jangkauan Ketempat Pelayanan Kesehatan di Wilayah Kerja Puskesmas Kota Kualasimpang Kabupaten Aceh Tamiang Tahun 2019

\begin{tabular}{clcc}
\hline No & $\begin{array}{l}\text { Jangkauan Ketempat } \\
\text { Pelayanan Kesehatan }\end{array}$ & n & \% \\
\hline 1 & Tidak Mudah & 48 & 61.5 \\
2 & Mudah Jumlah & 30 & 38.5 \\
\hline \multicolumn{2}{c}{ J8 } & $\mathbf{1 0 0 . 0}$ \\
\hline
\end{tabular}

Berdasarkan tabel 5. di atas dapat dilihat bahwa jangkauan ketempat pelayanan kesehatan mayoritas tidak lengkap sebanyak 48 orang $(61.5 \%)$

Tabel 6. Distribusi Frekuensi Dukungan Keluargadi Wilayah Kerja Puskesmas Kota Kualasimpang Kabupaten Aceh Tamiang Tahun 2019

\begin{tabular}{clcc}
\hline No & Dukungan Keluarga & $\mathbf{n}$ & \% \\
\hline 1 & Tidak Mendukung & 30 & 38.5 \\
2 & Mendukung & 48 & 61.5 \\
\hline \multicolumn{2}{r}{ Jumlah } & $\mathbf{7 8}$ & $\mathbf{1 0 0 . 0}$
\end{tabular}

Berdasarkan tabel 6. di atas dapat dilihat bahwa dukungan keluarga mayoritas mendukung sebanyak 48 orang $(61.5 \%)$.

Tabel 7 Distribusi Frekuensi Dukungan Petugas Kesehatandi Wilayah Kerja Puskesmas Kota Kualasimpang Kabupaten Aceh Tamiang Tahun 2019

\begin{tabular}{clcc}
\hline No & Dukungan Petugas Kesehatan & n & \% \\
\hline 1 & Tidak Mendukung & 30 & 38.5 \\
2 & Mendukung & 48 & 61.5 \\
\hline \multicolumn{2}{c}{ Jumlah } & $\mathbf{7 8}$ & $\mathbf{1 0 0 , 0}$
\end{tabular}

Berdasarkan tabel 7. di atas dapat dilihat bahwa dukungan petugas kesehatan mayoritas mendukung sebanyak 48 orang $(61.5 \%)$. 
Tabel 8 Distribusi Frekuensi Kunjungan K4 Pada Ibu Hamildi Wilayah Kerja Puskesmas Kota Kualasimpang Kabupaten Aceh Tamiang Tahun 2019

\begin{tabular}{|c|c|c|c|c|}
\hline No & $\begin{array}{lll}\text { Kunjungan } & \text { K4 } & \text { Pada } \\
\text { Hamil }\end{array}$ & Ibu & $\mathbf{n}$ & $\%$ \\
\hline 1 & Tidak Berkunjung & & 47 & 60.3 \\
\hline 2 & Berkunjung & & 31 & 39.7 \\
\hline & Jumlah & & 78 & 100.0 \\
\hline
\end{tabular}

Berdasarkan tabel 4.8 di atas dapat dilihat bahwa kunjungan $\mathrm{K} 4$ pada ibu hamil mayoritas tidak berkunjung sebanyak 47 orang $(60.3 \%)$.

\section{Analisa Bivariat}

Tabel 9. Tabulasi Silang Hubungan FaktorPengetahuan Ibu Hamil Dengan Kunjungan K4 Pada Ibu Hamil di Wilayah Kerja Puskesmas Kota Kualasimpang Kabupaten Aceh Tamiang Tahun 2019.

\begin{tabular}{|c|c|c|c|c|c|c|c|c|}
\hline \multirow{3}{*}{ No } & \multirow{3}{*}{$\begin{array}{l}\text { Pengetahuan } \\
\text { Ibu Hamil }\end{array}$} & \multicolumn{4}{|c|}{$\begin{array}{c}\text { Kunjungan K4 Pada Ibu } \\
\text { Hamil }\end{array}$} & \multirow{2}{*}{\multicolumn{2}{|c|}{ Total }} & \multirow{3}{*}{$\underset{\text { Value }}{p}$} \\
\hline & & \multicolumn{2}{|c|}{ Berkunjung } & \multicolumn{2}{|c|}{$\begin{array}{c}\text { Tidak } \\
\text { Berkunjung }\end{array}$} & & & \\
\hline & & $\mathrm{n}$ & $\%$ & $\mathbf{n}$ & $\%$ & n & $\%$ & \\
\hline 1 & Kurang & 12 & 15.4 & 31 & 39.7 & 43 & 55.1 & \\
\hline 2 & Cukup & 10 & 12.8 & 11 & 14.1 & 21 & 26.9 & 0.037 \\
\hline \multirow[t]{2}{*}{3} & Baik & 9 & 11.5 & 5 & 6.4 & 14 & 17.9 & \\
\hline & Total & 31 & 39.7 & 47 & 60.3 & 78 & 100.0 & \\
\hline
\end{tabular}

Berdasarkan tabel 4.9 dapat dilihat bahwa dari 43 orang responden(55.1\%)pengetahuan kunjungan K4 pada ibu hamil yang kurang terdapat 12 orang $(15.4 \%)$ yang berkunjung $\mathrm{K} 4$ dan 31 orang(39.7\%) yang tidak berkunjung K4. Namun dari 21 orang responden (26.9\%) pengetahuan yang cukup terdapat 10 orang (12.8\%) yang berkunjung K4 dan 11 orang(14.1\%) tidak berkunjung K4. Sedangkan dari 14 orang responden(17.9\%) pengetahuan kunjungan K4 pada ibu hamil yang baik terdapat 9 orang(11.5\%) yang berkunjung K4 dan 5 orang (6.4\%) yang tidak melakukan kunjungan K4. Dari hasil uji chi-square diperoleh $p$ value sebesar 0.037 $(\mathrm{p}<0.05)$ artinya ada hubungan yang signifikan pengetahuan ibu hamil dengan kunjungan K4 pada ibu hamil di Wilayah Kerja Puskesmas Kota Kualasimpang Kabupaten Aceh Tamiang.

Tabel 10.Tabulasi Silang Hubungan Paritas dengan Kunjungan K4 Pada Ibu Hamil di Wilayah Kerja Puskesmas Kota Kualasimpang Kabupaten Aceh Tamiang Tahun 2019

\begin{tabular}{|c|c|c|c|c|c|c|c|c|}
\hline \multirow{3}{*}{ No } & \multirow{3}{*}{ Paritas } & \multicolumn{4}{|c|}{$\begin{array}{c}\text { Kunjungan K4 Pada Ibu } \\
\text { Hamil }\end{array}$} & \multirow{2}{*}{\multicolumn{2}{|c|}{ Total }} & \multirow{3}{*}{$\underset{\text { Value }}{p}$} \\
\hline & & \multicolumn{2}{|c|}{ Berkunjung } & \multicolumn{2}{|c|}{$\begin{array}{c}\text { Tidak } \\
\text { Berkunjung }\end{array}$} & & & \\
\hline & & $\mathbf{n}$ & $\%$ & $\mathbf{n}$ & $\%$ & $\mathbf{n}$ & $\%$ & \\
\hline 1 & Primigravida & 12 & 15.4 & 7 & 9.0 & 19 & 24.4 & \\
\hline 2 & Multigravida & 13 & 16.7 & 18 & 23.1 & 31 & 39.7 & 0.014 \\
\hline 3 & $\begin{array}{l}\text { Grandemultig } \\
\text { ravida }\end{array}$ & 6 & 7.7 & 22 & 28.2 & 28 & 35.9 & \\
\hline & Total & 31 & 39.7 & 47 & 60.3 & 78 & 100.0 & \\
\hline
\end{tabular}


Berdasarkan tabel 10. dapat dilihat bahwa dari 19 orang responden(24.4\%) paritas dengan primigravida terdapat 12 orang(15.4\%) yang berkunjung $\mathrm{K} 4$ dan 7 orang(9.0\%) yang tidak berkunjung pada K4. Dari 31 orang responden (39.7\%) dengan multigravida terdapat 13 orang(16.7\%) yang berkunjung $\mathrm{K} 4$ dan 18 orang(23.1\%) yang tidak berkunjung pada K4. Sedangkan dari 28 orang responden (35.9\%) dengan grandemultigravida terdapat 6 orang $(7.7 \%)$ yang berkunjung $\mathrm{K} 4$ dan 22 orang $(28.2 \%)$ yang tidak berkunjung pada K4. Hasil uji chi-square diperoleh $p$ value sebesar $0.014(\mathrm{p}<0.05)$ artinya ada hubungan yang signifikan paritas dengan kunjungan K4 pada ibu hamil di Wilayah Kerja Puskesmas Kota Kualasimpang Kabupaten Aceh Tamiang.

Tabel 11.Tabulasi Silang Hubungan Ketersediaan Alat Pemeriksaan Kehamilan dengan Kunjungan K4 Pada Ibu Hamil di Wilayah Kerja Puskesmas Kota Kualasimpang Tahun 2019

\begin{tabular}{|c|c|c|c|c|c|c|c|c|}
\hline \multirow{3}{*}{ No } & \multirow{3}{*}{$\begin{array}{c}\text { Ketersediaan } \\
\text { Alat } \\
\text { Pemeriksaan } \\
\text { Kehamilan }\end{array}$} & \multicolumn{4}{|c|}{$\begin{array}{l}\text { Kunjungan K4 Pada Ibu } \\
\text { Hamil }\end{array}$} & \multirow{2}{*}{\multicolumn{2}{|c|}{ Total }} & \multirow{3}{*}{$\underset{\text { Value }}{p}$} \\
\hline & & \multicolumn{2}{|c|}{ Berkunjung } & \multicolumn{2}{|c|}{$\begin{array}{c}\text { Tidak } \\
\text { Berkunjung }\end{array}$} & & & \\
\hline & & n & $\%$ & $\mathbf{n}$ & $\%$ & $\mathbf{N}$ & $\%$ & \\
\hline \multirow[t]{2}{*}{1} & Tidak & 12 & 15.4 & 31 & 39.7 & 43 & 55.1 & \multirow{4}{*}{0.018} \\
\hline & Lengkap & & & & & & & \\
\hline \multirow[t]{2}{*}{2} & Lengkap & 19 & 24.4 & 16 & 20.5 & 35 & 44.9 & \\
\hline & Total & 31 & 39.7 & 47 & 60.3 & 78 & 100.0 & \\
\hline
\end{tabular}

Berdasarkan tabel 11. dapat dilihat bahwa 43 orang responden(55.1\%) ketersediaan alat pemeriksaan kehamilan yang tidak lengkap terdapat 12 orang(15.4\%) berkunjung K4 dan 31 orang $(39.7 \%)$ tidak berkunjung K4. Sedangkan dari 35 orang responden(44.9\%) ketersediaan alat pemeriksaan kehamilan yang lengkap terdapat 19 orang(24.4\%) yang berkunjung k4 dan 16 orang $(20.5 \%)$ yang tidak berkunjung $\mathrm{K} 4$. Berdasarkan hasil uji chi-square diperoleh $p$ valuesebesar $0.018(\mathrm{p}<0.05)$ yang artinya ada hubungan yang signifikan ketersediaan alat pemeriksaan kehamilan dengan kunjungan K4 pada ibu hamil di Wilayah Kerja Puskesmas Kota Kualasimpang Kabupaten Aceh Tamiang.

Tabel 12. Tabulasi Silang Hubungan Jangkauan Ke Tempat Pelayanan Kesehatan dengan Kunjungan K4 Pada Ibu Hamil di Wilayah Kerja Puskesmas Kota Kualasimpang Kabupaten Aceh Tamiang Tahun 2019

\begin{tabular}{|c|c|c|c|c|c|c|c|c|}
\hline \multirow{3}{*}{ No } & \multirow{3}{*}{$\begin{array}{c}\text { Jangkauan } \\
\text { Ke Tempat } \\
\text { Pelayanan } \\
\text { Kesehatan }\end{array}$} & \multicolumn{4}{|c|}{$\begin{array}{c}\text { Kunjungan K4 Pada Ibu } \\
\text { Hamil }\end{array}$} & \multirow{2}{*}{\multicolumn{2}{|c|}{ Total }} & \multirow{3}{*}{$\begin{array}{c}p \\
\text { Value }\end{array}$} \\
\hline & & \multicolumn{2}{|c|}{ Berkunjung } & \multicolumn{2}{|c|}{$\begin{array}{c}\text { Tidak } \\
\text { Berkunjung } \\
\end{array}$} & & & \\
\hline & & $\mathbf{N}$ & $\%$ & $\bar{n}$ & $\%$ & $\mathbf{N}$ & $\%$ & \\
\hline 1 & Tidak Mudah & 12 & 15.4 & 36 & 46.2 & 48 & 61.5 & \\
\hline 2 & Mudah & 19 & 24.4 & 11 & 14.1 & 30 & 38.5 & 0.001 \\
\hline & Total & 31 & 39.7 & 47 & 60.3 & 78 & 100.0 & \\
\hline
\end{tabular}

Berdasarkan tabel 12. dapat dilihat bahwa 48 orang responden(61.5\%) jangkauan ketempat pelayanan kesehatan yang tidak mudah terdapat 12 orang(15.4\%) yang berkunjung $\mathrm{K} 4$ dan 36 orang $(46.2 \%)$ yang tidak berkunjung K4. Sedangkan dari 30 orang responden (38.5\%) jangkauan 
ketempat pelayanan kesehatan yang mudah terdapat 19 orang(24.4\%) yang berkunjung K4 dan 11 orang $(14.1 \%)$ yang tidak berkunjung K4. Berdasarkan hasil uji chi-square diperoleh nilai $p$ value sebesar $0.001(\mathrm{p}<0.05)$ yang artinya bahwa terdapat hubungan yang signifikanjangkauan ketempat pelayanan kesehatan dengan kunjungan K4 pada ibu hamil di Wilayah Kerja Puskesmas Kota Kualasimpang Kabupaten Aceh Tamiang.

Tabel 13.Tabulasi Silang Hubungan Dukungan Keluarga dengan Kunjungan K4 pada Ibu Hamil di Wilayah Kerja Puskesmas Kota Kualasimpang Kabupaten Aceh Tamiang Tahun 2019

\begin{tabular}{|c|c|c|c|c|c|c|c|c|}
\hline \multirow{4}{*}{ No } & \multirow{4}{*}{$\begin{array}{c}\text { Dukungan } \\
\text { Keluarga }\end{array}$} & \multirow{2}{*}{\multicolumn{4}{|c|}{$\begin{array}{l}\text { Kunjungan K4 Pada Ibu } \\
\text { Hamil }\end{array}$}} & \multirow{3}{*}{\multicolumn{2}{|c|}{ Total }} & \multirow{4}{*}{$\begin{array}{c}p \\
\text { Value }\end{array}$} \\
\hline & & & & & & & & \\
\hline & & \multicolumn{2}{|c|}{ Berkunjung } & \multicolumn{2}{|c|}{$\begin{array}{c}\text { Tidak } \\
\text { Berkunjung }\end{array}$} & & & \\
\hline & & $\mathbf{n}$ & $\%$ & $\mathbf{n}$ & $\%$ & $\mathbf{n}$ & $\%$ & \\
\hline \multirow[t]{2}{*}{1} & Tidak & 6 & 7.7 & 24 & 30.8 & 30 & 38.5 & \multirow{4}{*}{0.005} \\
\hline & Mendukung & & & & & & & \\
\hline \multirow[t]{2}{*}{2} & Mendukung & 25 & 32.1 & 23 & 29.5 & 48 & 61.5 & \\
\hline & Total & 31 & 39.7 & 47 & 60.3 & 78 & 100.0 & \\
\hline
\end{tabular}

Berdasarkan tabel 13. dapat dilihat bahwa dari 30 orang responden(38.5\%) dukungan keluarga yang tidak mendukung terdapat 6 orang( $7.7 \%)$ yang berkunjung K4 dan 24 orang $(30.8 \%$ ) yang tidak berkunjung K4. Sedangkan dari 48 orang responden(61.5\%) dukungan keluarga yang medukung terdapat 25 orang (32.1\%) yang berkunjung K4 dan 23 orang(29.5\%) yang tidak berkunjung K4. Berdasarkan hasil uji chi-square diperoleh $p$ value sebesar 0.005 ( $\mathrm{p}<0.05)$ yang artinya terdapat hubungan yang signifikan dukungan keluarga dengan kunjungan K4 pada ibu hamil di Wilayah Kerja Puskesmas Kota Kualasimpang Kabupaten Aceh Tamiang.

Tabel 14. Hubungan Dukungan Petugas Kesehatan dengan Kunjungan K4 Pada Ibu Hamil di Wilayah Kerja Puskesmas Kota Kualasimpang Tahun 2019

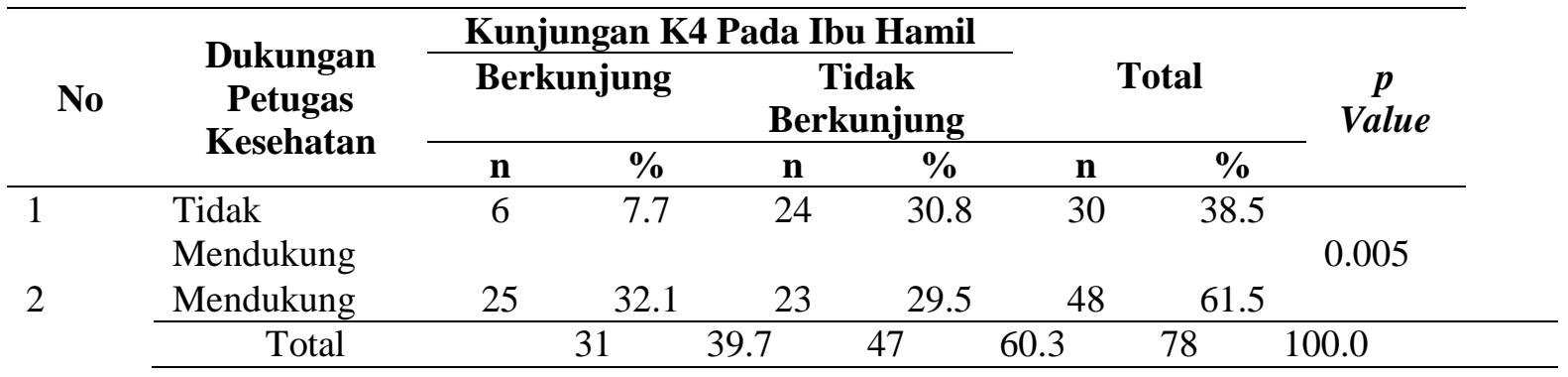

Berdasarkan tabel 14. dapat dilhat bahwa 30 orang responden(38.5\%) dukungan petugas kesehatan yang tidak mendukung terdapat 6 orang (7.7\%) berkunjung K4 dan 24 orang(30.8\%) yang tidak berkunjung K4. Sedangkan dari 48 orang responden $(61.5 \%)$ dukungan petugas kesehatan yang mendukung terdapat 25 orang (32.1\%) yang berkunjung K4 dan23 orang (29.5\%) yang tidak berkunjung K4. Berdasarkan hasil uji chi-square diperoleh nilai $p$ value $0.005(\mathrm{p}<0.05)$ yang artinya terdapat hubungan yang signifikan dukungan petugas kesehatan dengan kunjungan K4 pada ibu hamil di Wilayah Kerja Puskesmas Kota Kualasimpang Kabupaten Aceh Tamiang. 


\section{Analisis Multivariat}

Berdasarkan hasil Uji Logistik di dapat Variabel yang paling mempengaruhi adalah paritas $(\mathrm{p}=0.001 ; \mathrm{PR}=15.863$; 95\%CI:3.221-78.114) yang berarti bahwa responden dengan Paritas multigravida mempunyai risiko tidak melakukan kunjungan K4 15.863 kali lebih besar dibandingkan paritas primigravida.

Paritas yaitu salah satu faktor predisposisi yang mempengaruhi perilaku ibu untuk memanfaatkan pelayanan kesehatan dalam hal ini kunjungan (K4) (Notoatmodjo, 2010). Menurut Winkjoksastro (2008) dalam Choirunissa (2018) ibu hamil primigravidalebih ingin kehamilanya selalu dalam keadaan baik dan sehat karena belum mempunyaipengalaman tentang kehamilan sehingga dalam perjalanan kehamilan dan menuju persalinan selalu menjaga kehamilan supaya aman dan nyaman. Namun tidak sedikit pula ibu dengan paritas multigravida yang giat melakukan pemeriksaan kehamilan sampai kunjungan K4. Hal ini didasarkan oleh pengalaman ibu dari kehamilan yang sebelumnya. Ibu hamil dengan jumlah anak lebih sedikit cenderung akan lebih baik dalam memeriksakan kehamilannya daripada ibu hamil dengan jumlah anak lebih banyak.

Hal ini sejalan dengan penelitian yang dilakukan oleh Aisyah dkk (2015), menunjukkan ada hubungan paritas dengan frekuensi kunjungan pemeriksaan kehamilan dengan pvalue sebesar $0,043(<0,05)$.

\section{KESIMPULAN DAN SARAN \\ Kesimpulan}

Berdasarkan hasil penelitian di wilayah kerja Puskesmas Kota Kuala Simpang Kabupaten Aceh Tamiang dimana Ada hubungan pengetahuan, paritas, ketersediaan alat pemeriksaan kehamilan, jangkauan ketempat pelayanan kesehatan, dukungan keluarga, dukungan petugas kesehatan dengan kunjungan K4 pada ibu hamil di Wilayah Kerja Puskesmas Kota Kuala Simpang Kabupaten Aceh Tamiang Tahun 2019.

\section{Saran}

Adapun saran untuk petugas kesehatan yang berada di Wilayah Kerja Puskesmas Kota Kuala Simpang Kabupaten Aceh Tamiang Diharapkan kepada petugas kesehatan agar berperan aktif dalam membina setiap program yang ada di wilayah kerjanya serta mengupayakan untuk meningkatkan keaktifannya dalam menjangkau ibu hamil yang masih memiliki keterbatasan akses keterjangkauan dan meningkatkan pelaporan KIA. Selain itu, petugas kesehatan lebih meningkatkan kualitas pelayanan pemeriksaan kehamilan.

\section{Ucapan Terima Kasih}

Penulis mengucapkan terimakasih kepada kepala puskesmas Kota Kuala Simpang yang telah memberikan dukungan terhadap penelitian ini.

\section{REFERENSI}

Aisyah, R, D., Rusmariana, A., Mujiati, D. (2015). Frekuensi Kunjungan ANC (Antenatal Care) Pada Ibu Hamil Trimester III. Volume VIII. Nomor 2. Diakses pada tanggal 22 Februari 2019 melalui https://media.neliti.com/media/ publications/96887-ID.pdf 
Choirunissa, R., Syaputri, N, D. (2018). Analisis Faktor Yang Berhubungan Dengan Pemeriksaan K4 pada Ibu Hamil di Puskesmas Bakung Provinsi Lampung Tahun 2017. Jurnal Akademi Keperawatan Husada Karya Jaya, Volume 4, $\quad$ Nomor 1, Maret 2018 ISSN 2442-501X. diakses pada tanggal 09 Februari 2019 melalui ejurnal.husadakaryajaya.ac.id/index.php/JAKHKJ/article.pdf

Cholifah., Putri, N, A. (2015). Faktor-Faktor Yang Berpengaruh Terhadap Pencapaian K4 di Desa Sumberejo Wonoayu Sidoarjo. Vol. 1 ; No. 2. Diakses pada tanggal 28 Januari 2019 melalui https://www.researchgate.net /publication.pdf

Irianto, K. (2014). Biologi Reproduksi.Alfabeta. Bandung

Kementerian Kesehatan RI. (2015). Profil Kesehatan Indonesia. Diakses pada tanggal 29 Januari 2019 melalui http://www.depkes.go.id/resources/ down load/pusdatin/profilkesehatan-indonesia/profil-kesehatan-Indonesia.pdf.

Kementerian Kesehatan RI. (2016). Profil Kesehatan Indonesia Tahun $2015 . \quad$ Kemenkes RI. Jakarta

Notoatmodjo, S. (2010). Metodologi Penelitian Kesehatan. Rineka Cipta. Jakarta

Profil Kesehatan Kabupaten Aceh Tamiang. (2017). Profil Kesehatan Kabupaten Aceh Tamiang Tahun 2017. Diakses pada tanggal 08 Februari 2019 melalui http://www.depkes.go.id/resources/download/profil/PROFIL_KAB_KOTA_2017/1114_A ceh_Kab_Aceh_Tamiang_2017.pdf

Riset Kesehatan Dasar (Riskesdas). (2018). Hasil Utama Riskesdas 2018. Kementerian Kesehatan Badan Penelitian dan Pengembangan Kesehatan. Kementrian kesehatan RI. Diakses melalui http://www.depkes.go.id /resources/download/infoterkini/materi_rakorpop_2018/Hasil\%20Riskes das\%202018.pdf?opwvc=1.

World Health Organization (WHO). (2016). Global Health Observatory (GHO) Data. Available online http://www.who.int/gho/maternalhealth/mortality/mater nal/en/index2.html. 2 February 2019 